\title{
Lewis $X$ component in human milk binds DC-SIGN and inhibits HIV-1 transfer to CD4+ T lymphocytes
}

\author{
Marloes A. Naarding, ${ }^{1}$ Irene S. Ludwig,, ${ }^{2}$ Fedde Groot, ${ }^{1,3}$ Ben Berkhout,, ${ }^{1}$ Teunis B.H. Geijtenbeek, ${ }^{2}$ \\ Georgios Pollakis, ${ }^{1}$ and William A. Paxton ${ }^{1}$
}

\begin{abstract}
${ }^{1}$ Department of Human Retrovirology, Academic Medical Center, University of Amsterdam, Amsterdam, The Netherlands. 2Department of Molecular Cell Biology and Immunology, Vrije Universiteit Medical Center, Amsterdam, The Netherlands. ${ }^{3}$ Department of Cell Biology and Histology, Academic Medical Center, University of Amsterdam, Amsterdam, The Netherlands.
\end{abstract}

\begin{abstract}
DC-specific ICAM3-grabbing non-integrin (DC-SIGN), which is expressed on DCs, can interact with a variety of pathogens such as HIV-1, hepatitis C, Ebola, cytomegalovirus, Dengue virus, Mycobacterium, Leishmania, and Candida albicans. We demonstrate that human milk can inhibit the DC-SIGN-mediated transfer of HIV-1 to $\mathrm{CD}^{+} \mathrm{T}$ lymphocytes as well as viral transfer by both immature and mature DCs. The inhibitory factor directly interacted with DC-SIGN and prevented the HIV-1 gp120 envelope protein from binding to the receptor. The human milk proteins lactoferrin, $\alpha$-lactalbumin, lysozyme, $\beta$-casein, and secretory leukocyte protease inhibitor did not bind DC-SIGN or demonstrate inhibition of viral transfer. The inhibitory effect could be fully alleviated with an $\mathrm{Ab}$ recognizing the Lewis $\mathrm{X}\left(\mathrm{Le}^{\mathrm{X}}\right)$ sugar epitope, commonly found in human milk. $\mathrm{Le}^{\mathrm{X}}$ in polymeric form or conjugated to protein could mimic the inhibitory activity, whereas free $L^{X}{ }^{X}$ sugar epitopes could not. We reveal that a Le ${ }^{X}$ motif present in human milk can bind to DC-SIGN and thereby prevent the capture and subsequent transfer of HIV-1 to CD4 ${ }^{+} \mathrm{T}$ lymphocytes. The presence of such a DC-SIGN-binding molecule in human milk may both influence antigenic presentation and interfere with pathogen transfer in breastfed infants.
\end{abstract}

\section{Introduction}

DCs can capture an array of infectious agents and present their antigens to T lymphocytes. DCs express, among other receptors, the DC-specific ICAM3-grabbing non-integrin (DC-SIGN) receptor, a C-type lectin, which contains an external calcium-dependent mannose-binding lectin domain $(1,2)$. DC-SIGN interacts with the envelope glycoprotein gp120 of HIV-1, HIV-2, and SIV (3-8), as well as other pathogens such as hepatitis C $(9,10)$, Ebola (11), cytomegalovirus (12), Dengue virus (13), Mycobacterium (14-16), Leishmania (17, 18), Candida albicans (19), and Helicobacter pylori (20, 21). DC-SIGN has been implicated as playing an important role in HIV-1 transmission and the establishment of infection $(4,6$, $22-25)$. The interaction of HIV-1 with DC-SIGN can lead to infection of the DCs, or alternatively the virus can be internalized into a trypsin-resistant compartment prior to undergoing transfer to its main target cells, and this mechanism has been shown to greatly enhance infection of $\mathrm{T}$ cells in vitro $(26,27)$.

Mother-to-child transmission (MTCT) of HIV-1 accounts for the majority of HIV-1 infections among children (28). Transmission can occur either in utero, intrapartum, or through breastfeeding (29). It has been recognized that HIV-1 transmission via breastfeeding accounts for $40 \%$ of all MTCTs of HIV-1 $(30,31)$. Relatively

Nonstandard abbreviations used: DC-SIGN, DC-specific ICAM3-grabbing nonintegrin; iDC, immature DC; Le ${ }^{\mathrm{X}}$, Lewis X; $\mathrm{mDC}$, mature DC; L-SIGN, liver and lymph node-specific ICAM3-grabbing non-integrin; MTCT, mother-to-child transmission; PAA, polyacrylamide; R5, CCR5 coreceptor using HIV-1 isolate; SLPI, secretory leukocyte protease inhibitor; TCID, tissue culture infectious dose; X4, CXCR4 coreceptor using HIV-1 isolate.

Conflict of interest: The authors have declared that no conflict of interest exists.

Citation for this article: J. Clin. Invest. 115:3256-3264 (2005).

doi:10.1172/JCI25105. little is known with regard to HIV-1 present within human milk and how the virus is transmitted from mother to child. Children exposed to HIV-1 through breastfeeding will encounter both free viral particles as well as cell-associated virus $(32,33)$. Macrophages in human milk are found at varying concentrations during lactation (34) and are preferentially infected with viruses that utilize the CCR5 coreceptor for viral entry (R5) and that are typically associated with HIV-1 transmission $(35,36)$. Mammary epithelial cells are present in human milk, and these cells are predominantly infected with viruses utilizing the CXCR4 coreceptor (X4), virus strains that seldom undergo transmission $(37,38)$. $\mathrm{CD}^{+} \mathrm{T}$ lymphocytes are also present in human milk, and these cells can be infected with both R5 and X4 strains, depending on the cellular phenotype and cell activation status $(39,40)$. MTCT of HIV- 1 via breastfeeding is likely to require the transfer of virus across a mucosal barrier or via breaches in the mucosal surface. The interaction of the HIV-1 gp120 protein with DCs, shown to be present at high concentrations in the tonsils, the upper rim of the esophagus $(41,42)$, and the intestinal tract (43), may therefore heighten virus capture and transmission. Although DC-SIGN expression has not been analyzed on DCs from all the above-mentioned anatomical sites, high levels of expression have been reported in tonsil material (6).

Several of the proteins present in human milk have been shown to posses antimicrobial activity. Lactoferrin (44-46), lysozyme (47), and secretory leukocyte protease inhibitor (SLPI) $(48,49)$ have all been shown to exhibit anti-HIV-1 properties in vitro. On the contrary, $\beta$-casein has been shown to enhance HIV-1 infection of $\mathrm{CD}^{+} \mathrm{T}$ lymphocytes (44). Oligosaccharides present in human milk include lactodifucotetraose; lacto- $N$-fucopentaose (LNFP) I, II and III; and monofucosyllacto- $N$-hexaose III; among others (50-52). A number of sugar epitopes to be found in human milk 

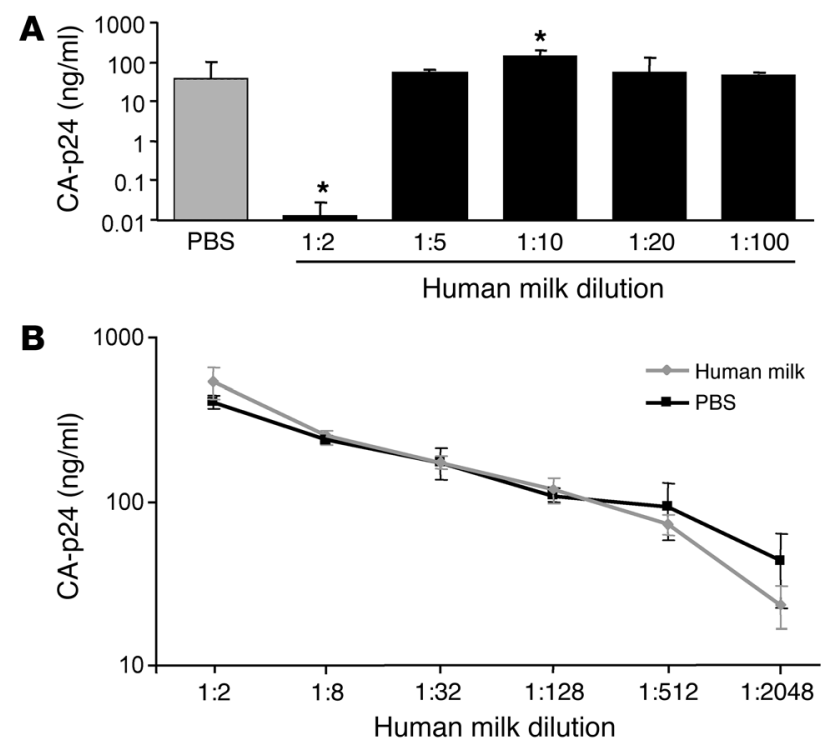

are composed of the Lewis group of antigens, including Lewis $\mathrm{X}$ $\left(\mathrm{Le}^{\mathrm{X}}\right)$ and Lewis $\mathrm{Y}\left(\mathrm{Le}^{\mathrm{Y}}\right)(53)$, which can be part of a larger oligosaccharide, regardless of whether the sugar is protein associated or not. The Le $\mathrm{X}^{\mathrm{X}}$ epitope (Gal $\beta 1-4[\mathrm{Fuc} \alpha 1-3]$ GlcNAc-R) is also included within the LNFP III sugar moiety. This same sugar epitope has been identified in bodily fluids, including saliva, blood, and human milk and has also been shown to be present in a number of pathogens (21) and pathogen extracts (54). Some of the human milk oligosaccharides have been shown to protect against toxins and pathogens involved in childhood diseases (55).

\section{Results}

The effect of human milk on direct HIV-1 infection of $C D 4^{+}$T lymphocytes and DC-SIGN-mediated HIV-1 transfer. We investigated the effect of human milk on direct infection of $\mathrm{CD}^{+} \mathrm{T}$ lymphocytes by incubating HIV-1 in the presence of several dilutions of human milk from an HIV-1-negative donor taken 6 months into lactation. The 2 -fold dilution of human milk demonstrated a significant degree of viral inhibition (>90\%; $P<0.05)$ in comparison with the PBS control (Figure 1A), which corresponds with previous reports (44-49). We also identify an enhancement to infection at the 1:10 dilution similar to findings from a previous study (38). Preincubation of the same human milk sample (1:2) with HIV-1 before addition

\section{Figure 2}

DC-SIGN-dependent transfer of HIV-1 to CD4+ $\mathrm{T}$ lymphocytes is inhibited in the presence of human milk. (A) A 1:2 dilution of human milk of an uninfected mother or PBS was spiked with primary isolates NSI-18 (R5) or SI-19 (X4) before addition to Raji-DC-SIGN cells. After an incubation of 30 minutes or 2 hours, the cells were washed, and activated $\mathrm{CD} 4{ }^{+} \mathrm{T}$ lymphocytes were added. Viral replication was measured on days $7,9,12$, and 14 after infection by determining CA-p24 values using a standard ELISA. The bars represent maximum and minimum CA-p24 values. (B) PBS or serial dilutions of human milk were spiked with JR-CSF (R5) or LAI (X4) before addition of Raji-DC-SIGN cells; after an incubation of 2 hours, the cells were washed with PBS, and stimulated CD4+ $\mathrm{T}$ lymphocytes were added. At day 7, CA-p24 concentrations were determined by standard ELISA. Percent inhibition was determined in reference to the CA-p24 concentration of the corresponding spiked PBS control.

\section{Figure 1}

Direct infection of CD4+ $\mathrm{T}$ lymphocytes in the presence of human milk. (A) PBS or several dilutions of human milk from an uninfected mother were spiked with LAI (X4) and added to CD4-enriched T lymphocytes. After a 2-hour incubation, the CD4+ $\mathrm{T}$ lymphocytes were washed, and fresh medium was added. (B) LAI (X4) was incubated with a 1:2 dilution of human milk or PBS for 2 hours, after which several dilutions were made and added to CD4+ $\mathrm{T}$ lymphocytes. For both experiments the CA-p24 concentration was determined on day $7 .{ }^{*} P<0.05 \mathrm{com}$ pared with the PBS control.

to $\mathrm{CD}^{+} \mathrm{T}$ lymphocytes (Figure $1 \mathrm{~B}$ ) showed no inhibitory effect in comparison to the PBS control, indicating that the inhibition shown in Figure 1A is not due to a direct virucidal effect of the milk and that the effect is likely conferred on the $\mathrm{CD} 4^{+}$lymphocyte. The experiments were repeated with human milk from 2 other mothers, with equivalent results obtained (data not shown).

DC-SIGN-expressing cells can enhance infection of $\mathrm{CD}^{+} \mathrm{T}$ lymphocytes $(4,8)$. To study the effect of human milk on DCSIGN-mediated transfer of HIV-1, we utilized the Raji cell line expressing the DC-SIGN receptor (Raji-DC-SIGN) (8). The same human milk sample as used in the direct infection assay or PBS spiked with HIV-1 primary isolates was incubated with the RajiDC-SIGN cells for 30 minutes or 2 hours, after which the cells were washed and incubated with activated $\mathrm{CD} 4^{+} \mathrm{T}$ lymphocytes and the culture monitored for viral replication. Raji-DC-SIGN cells preincubated with PBS spiked with HIV-1 showed efficient transfer to $\mathrm{CD}^{+} \mathrm{T}$ lymphocytes (Figure $2 \mathrm{~A}$, black line). The Raji cell line not expressing DC-SIGN showed no viral transfer, demonstrating that the effect we observed is DC-SIGN dependent (data not shown). Surprisingly, preincubation of Raji-DC-SIGN cells with HIV-1-spiked human milk significantly reduced or blocked transfer of HIV-1 depending on the incubation time (Figure 2A, gray line). Through testing cell viabilities, we demonstrated that the observed inhibition was not due to induced cell death of Raji-DCSIGN by human milk (data not shown). The transfer experiment revealed that human milk blocks the transfer of HIV-1 by Raji-DC-
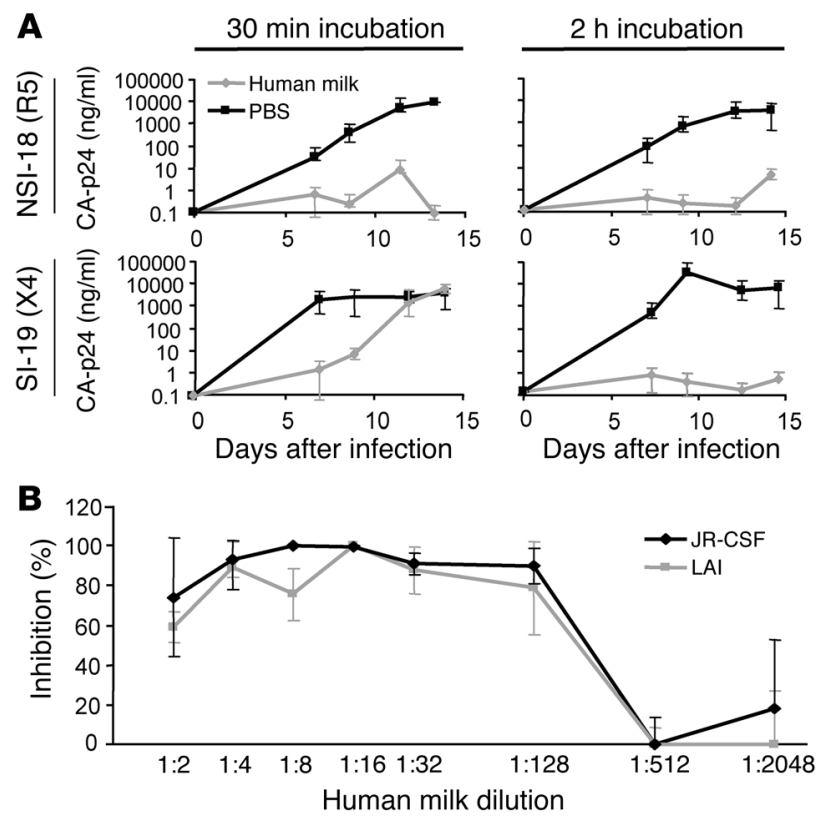

$2 \mathrm{~h}$ incubation

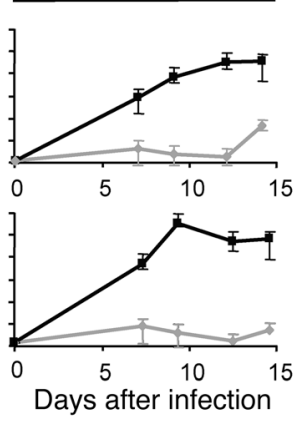



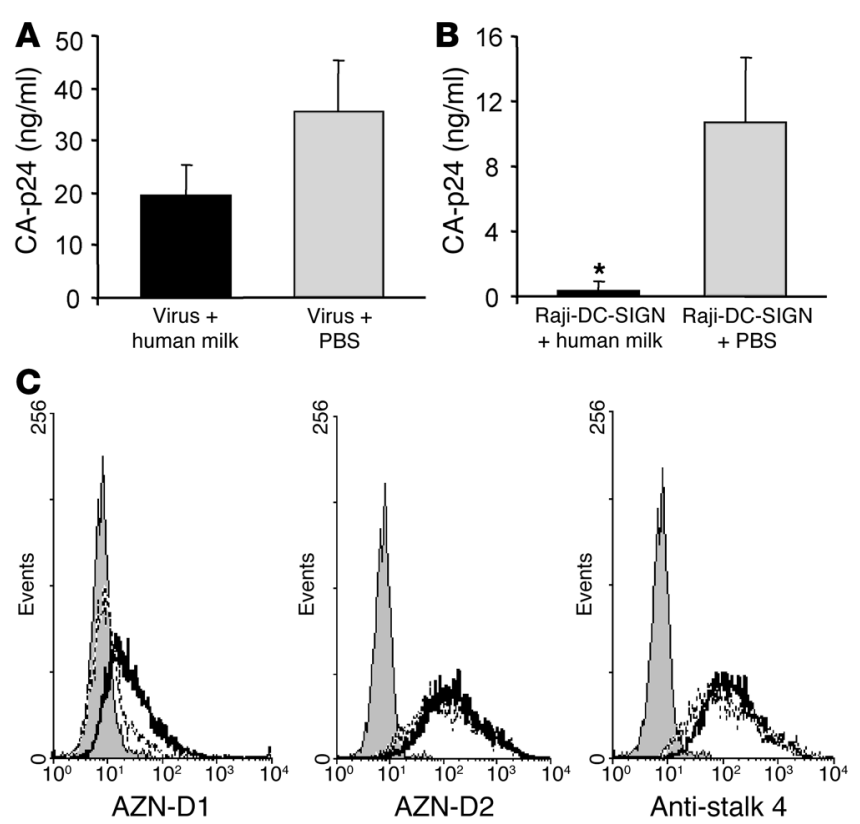

SIGN cells irrespectively of viral coreceptor phenotype. We next performed limiting dilutions of the same human milk sample and found that R5 and X4 HIV-1 variants were completely inhibited at a 1:128 but not at a 1:512 dilution (Figure 2B). Similar results were observed with the same assays using human milk from 2 other HIV-1-negative donors (data not shown).

Human milk compound(s) bind to DC-SIGN, thereby preventing transfer of HIV-1 to CD4+ Tlymphocytes. To determine whether the inhibitory effect of human milk on Raji-DC-SIGN-mediated viral transfer was caused by interaction of human milk with HIV-1 or DC-SIGN, we conducted preincubation experiments of either Raji-DC-SIGN cells or HIV-1 with human milk. To test for binding of the inhibitory factor to Raji-DC-SIGN cells, we preincubated the cells with either a known inhibitory concentration of human milk (1:4) or PBS before washing and then adding virus and subsequently $\mathrm{CD} 4^{+} \mathrm{T}$ lymphocytes. Alternatively, to test binding of components in human milk to the virus, we incubated a high-titer virus stock with either PBS or human milk, after which the Raji-DC-SIGN cells were added, thereby diluting the milk to a noninhibitory concentration (1:667); $\mathrm{CD}^{+} \mathrm{T}$ lymphocytes were then added. Preincubation of virus with human milk demonstrated a slight reduction in viral transfer com-

\section{Figure 4}

DC-SIGN-Fc binding ELISA and the gp120 bead adhesion assay demonstrate the interaction of the human milk compound(s) with DC-SIGN. (A and B) Raji-DC-SIGN cells or iDCs, respectively, were incubated with human milk (1:20) before addition of fluorescent gp120-coated beads. DC-SIGN-positive cells and mock Raji cells were incubated with buffer as controls. To determine the specificity of the observed binding, the cells were incubated with AZN-D1, EGTA, and mannan before addition of the gp120 beads. ${ }^{*} P<0.05$ compared with the PBS control. (C) Human milk (1:20) was coated before addition of DC-SIGN-Fc. The specificity of the observed binding was determined by the preincubation of DC-SIGN-FC with AZN-D1 and EGTA. ${ }^{* \star} P<0.01$ compared with the noninhibitory control. (D) Raji cells expressing the L-SIGN receptor were incubated with buffer, human milk (1:20), AZN-D1, AZN-D2, or mannan before addition of the gp120 fluorescent beads. ${ }^{\#} P<0.01$ compared with the binding without an inhibitor.

\section{Figure 3}

The human milk compound(s) interact with the DC-SIGN receptor, which does not lead to DC-SIGN downmodulation. (A) Human milk $(1: 4)$ or PBS was preincubated with a high-titer stock of LAI before adding to Raji-DC-SIGN cells at a dilution known not to inhibit viral replication. After incubation, the cells were washed, and CD4+ $T$ lymphocytes were added, with CA-p24 values measured on day 15 by standard ELISA $(P>0.01)$. (B) Human milk (1:4) or PBS were incubated with Raji-DC-SIGN, after which the cells were washed to remove unbound human milk components before addition of LAI. After incubation, the cells were washed again, and CD4+ T lymphocytes were added, with the CA-p24 values measured on day 15 by standard ELISA. ${ }^{*} P<0.01$. (C) Raji-DC-SIGN cells were incubated with TSM or human milk (1:2) before the binding of AZN-D1, AZN-D2, and anti-stalk 4 DC-SIGNspecific Abs were determined. The filled histograms represent the isotype control; the black lines represent the Ab binding without human milk preincubation; and the dotted lines represent the Ab binding after the cells were incubated with human milk. pared with the PBS control (Figure 3A), likely reflecting residual inhibitory effects of the human milk. In contrast, preincubation of the Raji-DC-SIGN cells with human milk provided a highly significant reduction in viral transfer compared with the PBS control $(P<0.01$; Figure 3B). To test whether the observed inhibition was due to downmodulation of DC-SIGN expression, we investigated the surface expression of DC-SIGN in the presence of human milk. We demonstrate that with 2 DC-SIGN-specific mAbs, AZN-D2 and anti-stalk 4, cell surface expression was not altered, whereas
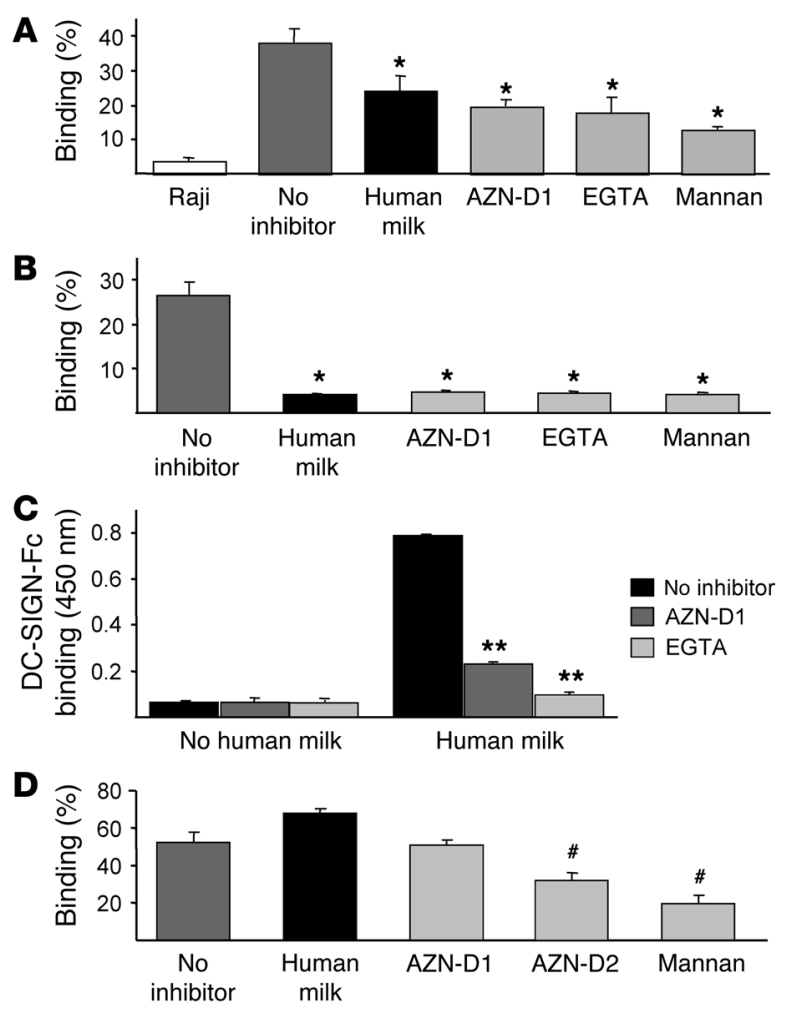
A

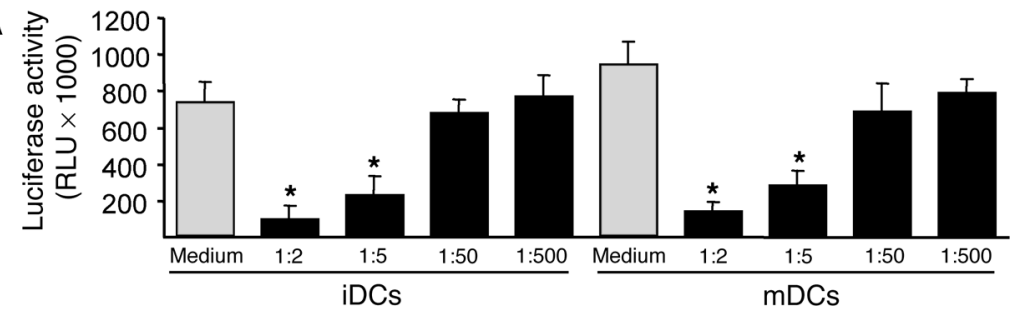

B

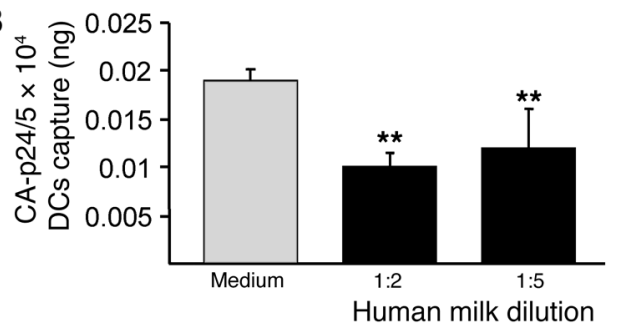

C

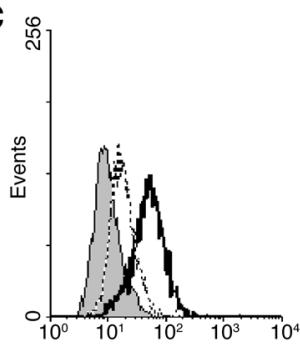

AZN-D1
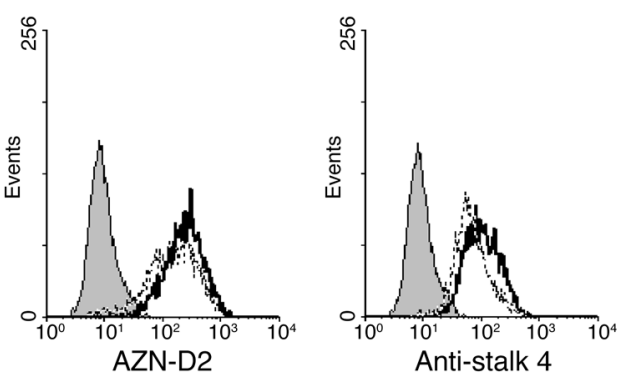

\section{Figure 5}

Human milk inhibits the transfer of HIV-1 by iDCs and mDCs. (A) Both iDCs and mDCs from the same donor were incubated with several dilutions of human milk for 30 minutes before addition of LAI (X4). After 2 hours the cells were washed, and LuSIV cells were added; after 24 hours the LuSIV cells were washed, and the luciferase activity was determined as described in Methods. The asterisks represent statistical differences in infections $(P<0.05)$. (B) After an incubation of iDCs with human milk or PBS, the cells were washed and LAI was added. After an incubation of 2 hours, the cells were washed again, and captured CA-p24 levels were monitored via ELISA. ${ }^{* *} P<0.05$ compared with the corresponding control value for both experiments. (C) iDCs were incubated with TSM or human milk (1:2) before the binding of AZN-D1, AZN-D2, and anti-stalk 4 DC-SIGN-specific Abs were determined. The filled histograms represent the isotype control; the black lines represent the $A b$ binding without human milk preincubation; and the dotted lines represent the Ab binding after the cells were incubated with human milk. the binding of AZN-D1 was reduced when DC-SIGN cells were preincubated with human milk (Figure 3C). These results suggest that the inhibitory effect is mediated via the binding of factor(s) in human milk to the DC-SIGN molecule and prevention of its interaction with HIV-1 as opposed to the downmodulation of the DC-SIGN molecule at the cell surface.

To show direct binding of human milk compound(s) to DCSIGN, we introduced 2 previously described assays $(6,56)$, the gp120 bead adhesion assay and the DC-SIGN-Fc binding ELISA. In the gp120 bead adhesion assay, the effect of human milk on the binding of gp120-coated fluorescent beads to cellular DC-SIGN was studied. The binding of the gp120 beads to both Raji-DC-SIGN and immature DCs (iDCs) was inhibited by human milk in comparison with the control ( $P<0.01$; Figure 4 , A and B, respectively). To demonstrate DC-SIGN-specific binding, the cells were preincubated with a DC-SIGN-specific Ab (AZN-D1), the DC-SIGN-binding sugar mannan, and the $\mathrm{Ca}^{2+}$ chelator EGTA. These agents were found to block binding of gp120 beads to the DC-SIGN-expressing cells to the same extent as human milk (Figure 4, A and B). To confirm the direct interaction of DC-SIGN with human milk, we performed a DC-SIGN-Fc binding ELISA where we demonstrated that DC-SIGN-Fc binding to human milk was specific, since preincubation of DC-SIGN-Fc with AZN-D1 or EGTA completely abrogated binding $(P<0.01$; Figure $4 \mathrm{C})$.

The liver and lymph node-specific homolog of DC-SIGN (liver and lymph node-specific ICAM3-grabing non-integrin [L-SIGN]) is also capable of interacting with HIV-1 and enhancing viral infectivity (57). To investigate the effect of human milk on the interaction of L-SIGN and gp120, we incubated Raji cells expressing the L-SIGN molecule (Raji-L-SIGN) with human milk in the gp120 bead adhesion assay, and as a control, the cells were preincubated with AZN-D1, AZN-D2 (an L-SIGN-specific Ab), mannan, and EGTA. The results demonstrated that human milk did not inhibit the interaction of gp120 with L-SIGN (Figure 4D), indicating a specificity of the human milk compound for DC-SIGN.

Human milk inhibits both iDC-and mature DC-dependent transfer of $H I V-1$. To study the biological relevance of the inhibitory properties of human milk, we utilized a previously described singlecycle HIV-1 transmission assay (58) using both iDCs and mature DCs (mDCs). Either iDCs or mDCs [matured by poly d(I-C)] were incubated with several dilutions of human milk before addition of HIV-1 LAI (X4) and target cells. After 24 hours, luciferase activity was measured, representing transmission of HIV-1 to the LuSIV cells. Human milk was found to inhibit HIV-1-mediated transfer by both iDCs and mDCs (Figure 5A) in a dose-dependent manner, with the 2 - and 5-fold dilutions showing significant inhibition for both cell types $(P<0.01)$. Washing after the preincubation of mDCs with human milk (1:2) before addition of HIV-1 also showed a significant reduction $(P<0.01)$ in HIV-1 transfer in comparison to the PBS control (data not shown), indicating that the observed inhibition shown in Figure 5A was not due to a direct virucidal effect of the human milk. We also demonstrated that a $1: 2$ and $1: 5$ dilution of human milk significantly reduces HIV-1 capture by iDCs $(P<0.01$; Figure $5 \mathrm{~B})$. We also tested for DC-SIGN downmodulation through cell-surface staining with the different Abs directed against DC-SIGN (AZN-D1, AZN-D2, and anti-stalk 4) in the presence or absence of human milk. Both AZN-D2 and anti-stalk 4 showed no significant difference in binding before and after human milk exposure, indicating that the DC-SIGN receptor is not downmodulated by the interaction with human milk (Figure 5C), while AZN-D1 does show a reduced binding after human milk exposure. We expect that similar results would 


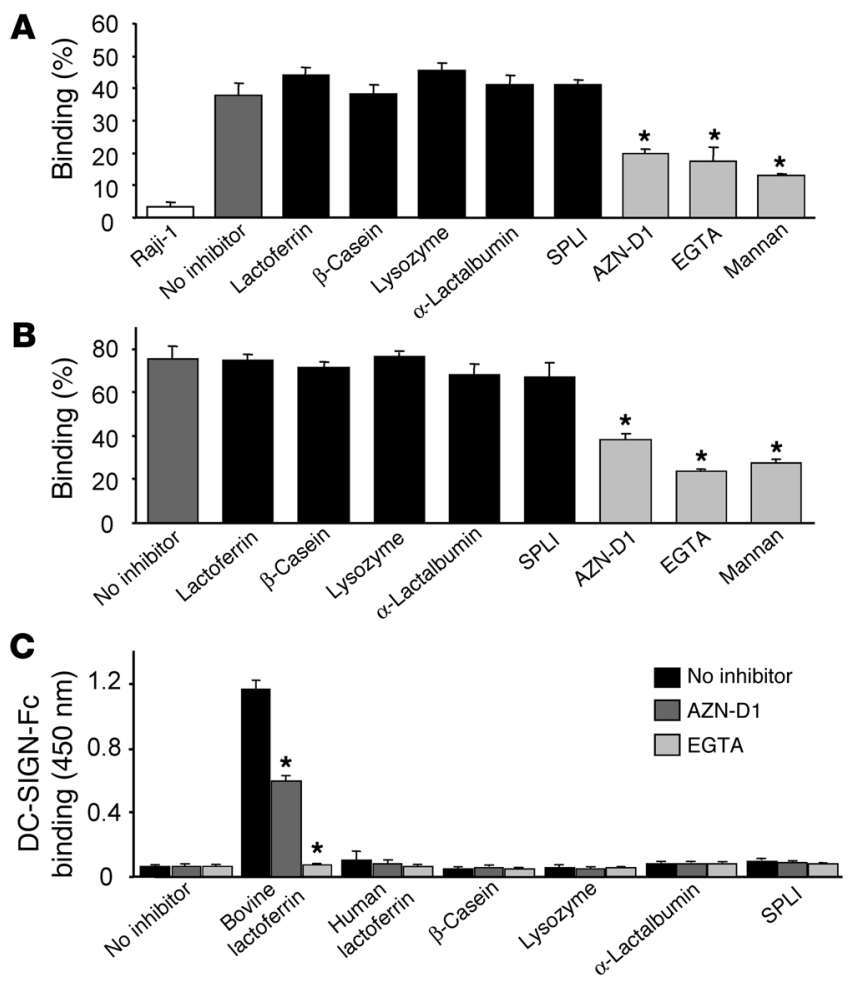

be obtained with an R5 virus and a CCR5-expressing cell, since we demonstrated that $\mathrm{R} 5$ and $\mathrm{X} 4$ viruses are equally inhibited with human milk (Figure 2).

Major buman milk proteins do not bind DC-SIGN nor inbibit HIV-1 transfer to $\mathrm{CD}^{+} \mathrm{T}$ lymphocytes. Since inhibition by human milk is present at relatively high dilutions (Figure 2B), we hypothesized that one of the major proteins present in human milk may be responsible for the activity. We therefore tested human lactoferrin, bovine $\beta$-casein, human lysozyme, human $\alpha$-lactalbumin, and human SLPI, which have been shown to posses modulatory effects on HIV-1 replication in vitro (44-49). All these compounds were tested in the gp120 bead adhesion assay and the DC-SIGN-Fc binding ELISA (Figure 6). None of the tested human milk compounds could inhibit gp120 binding to Raji-DC-SIGN or iDCs (Figure 6 , A and B, respectively). Furthermore, DC-SIGN-Fc showed no binding to the selected milk compounds (Figure 6C). As a control, bovine lactoferrin was used, which has previously been shown to bind DC-SIGN and prevent viral transfer (58).

\section{Figure 7}

Incubation of human milk (1:20) with Lex IgM Ab relieves the inhibitory properties of human milk on DC-SIGN-mediated transfer of HIV-1 to CD4+ $\mathrm{T}$ lymphocytes. (A) A 1:200 dilution of human milk was incubated alone, with lgM control $\mathrm{Ab}(4,000 \mathrm{ng} / \mathrm{ml})$, or with serial dilutions of Lex IgM Ab (4,000 to $32.7 \mathrm{ng} / \mathrm{ml})$ before addition of Raji-DC-SIGN cells. LAI was added, and following a short incubation, the cells were washed, and activated CD4+ $T$ lymphocytes were added, with CA-p24 values determined at day 7. ${ }^{*} P<0.05$ compared with the Raji-DCSIGN control. (B) Human milk (1:200) was coated and preincubated with anti-Lex IgM Ab $(4,000 \mathrm{ng} / \mathrm{ml})$ or an IgM control Ab $(4,000 \mathrm{ng} / \mathrm{ml})$ before addition of DC-SIGN-FC to determine binding. DC-SIGN-FC was preincubated with AZN-D1and EGTA to determine the specificity of the observed binding. ${ }^{* \star} P<0.01$ compared with the human milk binding without Ab present.

\section{Figure 6}

The major milk proteins are not responsible for the inhibitory effect of human milk. (A and B) Raji-DC-SIGN cells or iDCs were incubated with the major milk proteins before addition of fluorescent gp120coated beads; control cells were incubated with buffer. To determine the specificity of the observed binding, the cells were incubated with AZN-D1, EGTA, and mannan before addition of the gp120 beads. The asterisks represent $P<0.01$ compared with noninhibitory control. (C) The major milk proteins were coated on ELISA plates, and DC-SIGNFc binding was measured. To determine the specificity of the observed binding, the DC-SIGN-FC was preincubated with AZN-D1 and EGTA. ${ }^{\star} P<0.01$ compared with both the AZN-D1 and EGTA control. In all experiments the major proteins were diluted to a 1:20 dilution of their physiological concentration in human milk.

Preincubation of human milk with an anti-Le ${ }^{X} A b$ lifted the inbibition of HIV-1 transfer. Since DC-SIGN can bind sugars, we hypothesized that one of the abundant sugar motifs in human milk may provide the inhibitory activity (50-52). The fact that we demonstrated that gp120 binding to L-SIGN could not be inhibited with human milk (Figure 4D) and it is known that L-SIGN does not bind $\mathrm{Le}^{\mathrm{X}}$ motifs, we predicted that $\mathrm{Le}^{\mathrm{x}}$ could be contributing to the observed inhibition. To test our hypothesis, we preincubated human milk with an anti-Le ${ }^{\mathrm{X}} \operatorname{IgM} \mathrm{Ab}$ or an IgM isotype control before use in the culture transfer assay. The results demonstrated a dose-dependent lifting of the inhibitory effects of human milk on viral transfer after a preincubation with the $\mathrm{Le}^{\mathrm{X}}$-specific $\mathrm{Ab}$ but not with the control Ab (Figure 7A). In contrast, the gp120 bead adhesion assay did not show reduced binding of DC-SIGN with $\mathrm{Le}^{\mathrm{X}} \mathrm{Ab}$ (data not shown). The most likely explanation for this difference is that the low-affinity $\mathrm{Le}^{\mathrm{X}}$-specific $\mathrm{Ab}$ was unable to block the high-avidity interaction of cellular multimeric DC-SIGN to the unknown human milk component. The DC-SIGN-Fc binding ELISA (Figure 7B) demonstrated a reduction in DC-SIGN-FC binding after preincubation of the coated human milk with the $\mathrm{Le}^{\mathrm{X}}$-specific $\mathrm{Ab}$ but again not with the control $\mathrm{Ab}$. These results indicate that $\mathrm{Le}^{\mathrm{x}}$ is critical for the human milk compound that binds to the DC-SIGN molecule.

Not all Le $e^{X}$-containing complexes can inhibit HIV-1 interacting with the DC-SIGN receptor. We tested several compounds containing

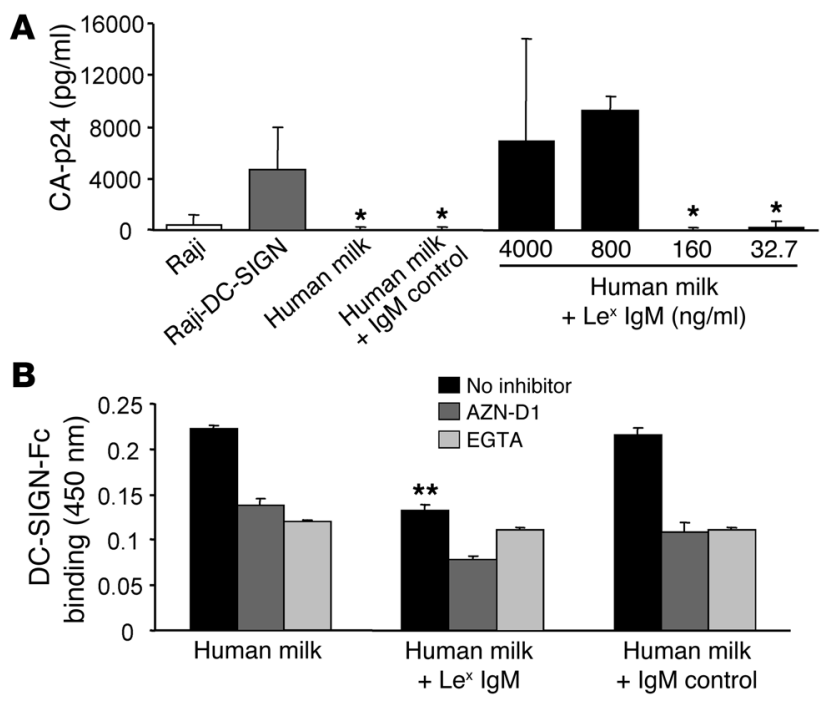


A

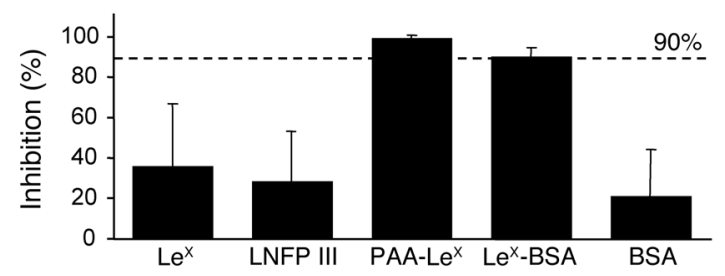

B

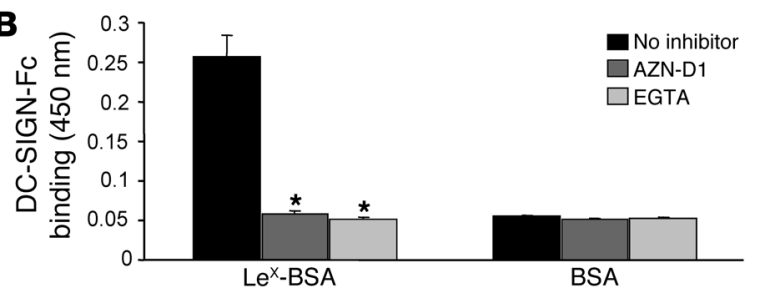

\section{Figure 8}

Multimeric and protein-associated $\mathrm{Le}^{\mathrm{X}}$ inhibits DC-SIGN-mediated viral transfer. (A) Several Le ${ }^{\mathrm{x}}$-containing compounds showed a difference in their ability to block DC-SIGN-dependent transfer of HIV-1 to CD4+ $\mathrm{T}$ lymphocytes. The Le ${ }^{\mathrm{X}}$ trisaccharide, LNFP III, PAA-Le ${ }^{\mathrm{X}}$, Le ${ }^{\mathrm{X}}-\mathrm{BSA}$, and control BSA were tested in the Raji-DC-SIGN culture transfer assay at concentrations of $10 \mu \mathrm{g} / \mathrm{ml}$. The inhibition is depicted as a percentage of the Raji-DC-SIGN incubated with PBS. (B) Le $\mathrm{e}^{\mathrm{x}}$-BSA and BSA as a control were coated before addition of DC-SIGN-Fc to determine the binding. DC-SIGN-FC was preincubated with AZN-D1and EGTA to determine the specificity of the observed binding. ${ }^{*} P<0.01$ compared with both the AZN-D1 and EGTA control.

one or more Le ${ }^{\mathrm{x}}$ epitopes for inhibitory and DC-SIGN binding activity. In the transfer culture assay, $\mathrm{Le}^{\mathrm{X}}$ coupled to biotinylated polyacrylamide $\left(\mathrm{PAA}-\mathrm{Le}^{\mathrm{X}}\right.$ ) and $\mathrm{Le}^{\mathrm{X}}$-BSA were both able to inhibit DC-SIGN-mediated HIV-1 transfer (Figure 8A). On the contrary, both LNFP III, a Le ${ }^{\mathrm{X}}$-containing oligosaccharide present in human milk, and the Lex trisaccharide itself were unable to prevent HIV-1 transfer (Figure 8A), even though LNFP III has been shown previously to bind DC-SIGN (59). The compounds were also tested in the gp120 bead adhesion assay, but none of the tested compounds were able to block the interaction between DC-SIGN and gp120 (data not shown). Most likely, PAA-Le ${ }^{\mathrm{X}}$ and Le ${ }^{\mathrm{X}}$-BSA are able to block the trimeric gp120 interaction, while binding of DC-SIGN to monomeric gp120 expressed on the fluorescent beads is still possible. Due to the inability to coat saccharides onto plates in the DC-SIGN-Fc binding ELISA, we only tested Le ${ }^{\mathrm{X}}$-BSA and the BSA control. Le ${ }^{\mathrm{X}}-\mathrm{BSA}$ indeed demonstrates binding to DC-SIGN-Fc, whereas BSA showed no binding, indicating that the DC-SIGN-FC binding is $\mathrm{Le}^{\mathrm{X}}$ specific (Figure $8 \mathrm{~B}$ ).

\section{Discussion}

C-type lectins, such as the DC-SIGN molecule, expressed on DCs have been postulated to play an important role in HIV-1 transmission and the establishment of initial HIV-1 infection $(1,2,4,6$, 22-25). The interaction of DC-SIGN with the HIV-1 gp120 surface antigen can result in the efficient presentation of the virus to its target cells and can greatly heighten infection and virus replication $(4,6,22-25)$. This mechanism is likely to play a role in MTCT of HIV-1 through breastfeeding, since virus transfer is required across a mucosal barrier. Virus present in human milk will likely encounter DCs situated at high concentrations within the tonsils, the esophagus $(41,42)$, and the intestines (43) that will thereby aid virus capture and subsequent transfer to $\mathrm{CD} 4^{+}$lymphocytes at the site of infection or in localized lymph nodes. In this study we demonstrate that human milk has a strong inhibitory effect on the DC-SIGN-mediated transfer of HIV- 1 to $\mathrm{CD} 4^{+} \mathrm{T}$ lymphocytes, with $\mathrm{R} 5$ and $\mathrm{X} 4$ viruses being inhibited to the same extent. A component in human milk is interacting with the DC-SIGN molecule that prevents HIV-1 from binding to the receptor. We showed that lactoferrin, $\alpha$-lactalbumin, lysozyme, $\beta$-casein, and SLPI were not responsible for the observed inhibition of HIV-1 interaction with DC-SIGN, even though these proteins can alter the direct infection of $\mathrm{CD}^{+} \mathrm{T}$ lymphocytes in vitro (44-49). Our results demonstrating that multimeric and protein-associated $\mathrm{Le}^{\mathrm{x}}$ motifs can mimic the inhibitory activity of human milk and that the activity could be alleviated with a mAb recognizing the $\mathrm{Le}^{\mathrm{X}}$ epitope suggest that a $\mathrm{Le}^{\mathrm{X}}$ component in human milk is providing for the inhibition.

In the majority of our experiments, we utilized the DC-SIGNexpressing cell line (Raji-DC-SIGN) and the control Raji cell lacking DC-SIGN in order to demonstrate the DC-SIGN specificity of our results (8). We have also shown that human milk inhibits transfer of HIV-1 by both iDCs and mDCs, illustrating the biological relevance of the phenomenon, again with the inhibition being due to prevention of binding rather than DC-SIGN downmodulation. The expression levels of DC-SIGN have previously been shown to be higher on iDCs than mDCs (60); however, the human milk inhibited viral transfer by both cell types. This result indicates that the observed inhibition of mDC-dependent transfer may reflect the ability of human milk to block transfer of HIV-1 by other C-type lectins, such as the mannose receptor or the unidentified trypsin-resistant receptor (61). Whether the same $\mathrm{Le}^{\mathrm{x}}$-containing compound(s) or whether other sugar motifs in human milk can bind to other C-type lectin receptors remains to be determined. We did demonstrate, however, that the binding of HIV-1 to the DC-SIGN homolog L-SIGN is not inhibited by human milk. Our result corresponds with the previous observation that Le ${ }^{\mathrm{X}}$ present in Schistosoma mansoni egg antigens (54) is able to interact with DC-SIGN but not with L-SIGN (62), reconfirming $\mathrm{Le}^{\mathrm{X}}$ as a candidate for the observed inhibition of DCSIGN-mediated transfer of HIV-1.

PAA-Le ${ }^{\mathrm{X}}$ and $\mathrm{Le}^{\mathrm{X}}$-BSA successfully inhibited the DC-SIGNmediated transfer of HIV-1. Conversely, both monomeric Lex trisaccharide and LNFP III, a human milk sugar, do not inhibit viral transfer. Even though LNFP III has been shown previously to bind to DC-SIGN (59), this interaction does not lead to sufficient blocking of the HIV-1 interaction with DC-SIGN nor prevent viral transfer to $\mathrm{CD}^{+} \mathrm{T}$ lymphocytes. Multimeric $\mathrm{Le}^{\mathrm{x}}$ was not able to inhibit gp120-coated beads binding to cellular DC-SIGN, possibly due to the high avidity of this interaction or the difference in interaction of the monomeric expression of gp120 on the fluorescent beads in comparison to trimeric expression of gp120 on the HIV-1 particle. The observed difference in the ability of $\mathrm{Le}^{\mathrm{X}} \mathrm{Ab}$ to block the inhibitory effect of human milk in the Raji-DC-SIGN transfer assay and the ELISA assay is possibly the result of differences in DC-SIGN configuration. On the cell surface, DC-SIGN is present as a tetramer, whereas in the DC-SIGN-Fc ELISA, the receptor is most likely a monomer or dimer, possibly leading to a weaker interaction. These differences in the configurations of the DC-SIGN molecules tested in the different assays suggest that caution should be applied when interpreting the results. It has been reported in previous studies that the $\mathrm{Le}^{\mathrm{X}}$ and the gp120 binding sites are distinct but overlapping $(54,56,63)$. An explanation for our observed inhibition by human milk could be that the larger 
compounds block the interaction of gp120 and DC-SIGN through steric hindrance by the larger tail. DC-SIGN forms a tetrameric structure on the cell surface (1) which could also cause occlusion of the gp120 binding site by interaction of several $\mathrm{Le}^{\mathrm{X}}$ residues with different monomeric DC-SIGN receptors. Most likely the interaction of several Le $\mathrm{e}^{\mathrm{X}}$ motifs with the tetrameric DC-SIGN leads to a much stronger interaction of the compound and again prevents sufficient binding of gp120 and subsequent viral transfer.

It has been previously demonstrated that DC-SIGN can interact with an array of other pathogens, including hepatitis $C(9,10)$, Ebola (11), cytomegalovirus (12), and Dengue virus (13), as well as Mycobacterium (14-16), Leishmania $(17,18)$, Candida albicans (19), and Helicobacter pylori $(20,21)$. Interaction of Le $\mathrm{X}^{\mathrm{x}}$-containing human milk compounds with DC-SIGN may influence the immune responses mounted in the child to incoming pathogens by preventing their interaction with the DCs and thereby prevent the presentation of pathogen-specific antigens and the subsequent activation of $\mathrm{CD} 4^{+} \mathrm{T}$ lymphocytes. This may be a mechanism whereby levels of immune activation are buffered in a newborn to prevent overstimulation of the immune system or to skew specific immune responses in a certain direction. Indeed, it has previously been reported that mice immunized intranasally with LNFP III-HSA demonstrated a stronger induction of Th2type immune responses versus Th1 (64). This result corresponds with the fact that $\mathrm{Le}^{\mathrm{X}}$-positive Helicobacter pylori interactions with DC-SIGN can block Th1-induced cell responses, which results in a relative enhancement of the Th2 cell response (21), suggesting that $\mathrm{Le}^{\mathrm{x}}$ compounds can influence the immune responses generated and that $\mathrm{Le}^{\mathrm{X}}$ compounds in human milk can function as immunomodulatory factors. It will therefore be interesting to investigate whether breastfed versus bottle-fed infants have differences in their immune responses mounted against orally transmitted pathogens. It has also been reported that the baseline activation of lymphocytes is higher in bottle-fed than in breastfed infants (65). A number of explanations have been hypothesized, including differences in exposure to foreign proteins or a higher variety in intestinal microflora. Another possibility is that human milk compounds containing the $\mathrm{Le}^{\mathrm{x}}$ motif buffers the immune response by binding DC-SIGN and that these compounds are absent in formula or cow milk.

Future work will have to determine the biological significance of the interaction of the $\mathrm{Le}^{\mathrm{x}}$-containing compounds with DCSIGN with regard to the stimulation of the immune system and the relevance for MTCT of HIV-1 and other pathogens. Further identification and characterization of the specific $\mathrm{Le}^{\mathrm{X}}$-containing compound(s) interacting with DC-SIGN may have major implications for the development of antimicrobial agents aiming at preventing HIV-1 transmission not only through breastfeeding but also through sexual activity.

\section{Methods}

Cells. The Raji control cell line and the cell lines expressing either DC-SIGN (Raji-DC-SIGN) or L-SIGN (Raji-L-SIGN) were cultured as previously described (4). PBMCs were isolated from buffy coats by standard FicollHypaque density centrifugation, activated with phytohemagglutinin (3 $\mu \mathrm{g} / \mathrm{ml})$, and cultured in RPMI medium containing $10 \% \mathrm{FCS}$, penicillin (100 units $/ \mathrm{ml}$ ), and streptomycin (100 units $/ \mathrm{ml})$. On day 3 the cells underwent $\mathrm{CD} 4^{+}$enrichment by incubation with CD8 immunomagnetic beads (Dynal Biotech) and were negatively selected according to the manufacturer's instructions and cultured with IL-2 $(100 \mathrm{U} / \mathrm{ml})$. DCs for the single-cycle transmission assay were generated from fresh PBMCs with cells layered on a standard Percoll gradient (Amersham Pharmacia). The light fraction with predominantly monocytes was collected, washed, and seeded in 24-well or 6-well culture plates at a density of $5 \times 10^{5}$ cells or $2.5 \times 10^{6}$ per well, respectively. After 60 minutes at $37^{\circ} \mathrm{C}$, the adherent cells were cultured to obtain iDCs in Iscove's modified Dulbecco's medium (IMDM) with gentamicin $(86 \mu \mathrm{g} / \mathrm{ml})$ and $10 \%$ fetal clone serum (HyClone) supplemented with GM-CSF $(500 \mathrm{U} / \mathrm{ml})$ and IL-4 $(250 \mathrm{U} / \mathrm{ml})$. Culture medium was refreshed on day 3 , with cell maturation induced at day 6 by culturing with poly(I:C) (20 $\mu \mathrm{g} / \mathrm{ml}$; Sigma-Aldrich). After 2 days, mature CD14-CD $1 \mathrm{~b}^{+} \mathrm{CD} 83^{+} \mathrm{DCs}$ were obtained, washed, and utilized. The culture conditions for LuSIV cells with an integrated long terminal repeat-luciferase reporter construct have been described previously (66).

Viruses. Replication-competent HIV-1 stocks were generated by the passage of viruses through $\mathrm{CD} 4^{+}$lymphocytes, with tissue culture infectious dose $\left(\mathrm{TCID}_{50} / \mathrm{ml}\right)$ determined by limiting dilution on $\mathrm{CD}^{+}$-enriched lymphocytes (67). Subtype B molecular cloned viruses JR-CSF (R5), LAI (X4), and SF-162 (R5) and subtype B primary isolates NSI-18 (R5) and SI-19 (X4) were used in the experiments.

Human milk fractions and commercial milk products. Internal review board approval was not required because samplings were taken from discarded material from a single time point. Human milk samples were sequentially centrifuged at $400 \mathrm{~g}$ and $530 \mathrm{~g}$ for 10 minutes, with pipette removal of the lipid layers. Samples were sterilized by filtration through both $0.45-\mu \mathrm{m}$ and $0.2-\mu \mathrm{m}$ syringe filters (Schleicher $\&$ Schuell BioScience Inc.) and stored at $-80^{\circ} \mathrm{C}$. Human lactoferrin (Sigma-Aldrich), bovine lactoferrin (SigmaAldrich), human $\alpha$-lactalbumin (Sigma-Aldrich), bovine $\beta$-casein (NIZO Food Research), human lysozyme (Sigma-Aldrich), LNFP III (Calbiochem), SLPI (Sigma-Aldrich), $\mathrm{Le}^{\mathrm{X}}$ trisaccharide (Calbiochem), Le ${ }^{\mathrm{X}}$-BSA, 14-atom spacer (Calbiochem), PAA-Le ${ }^{\mathrm{X}}$ (Syntesome), anti-human $\mathrm{Le}^{\mathrm{X}}$ (mouse) IgM (Calbiochem), and anti-human ARA-LAM (mouse) IgM were used. All compounds were utilized at physiologically relevant concentrations by dilution in PBS containing 10\% FCS.

Direct HIV-1 infection assay. Enriched CD4+ lymphocytes were plated in 96well plates at $1 \times 10^{5}$ cells/well in IL-2-containing culture medium. Cells were incubated for 2 hours with human milk diluted in PBS containing $10 \%$ FCS and spiked with $3.7 \log \mathrm{TCID}_{50} / \mathrm{ml}$ of HIV-1. After 2 hours the cells were washed and fresh medium added. Alternatively, after a 2-hour incubation of human milk with HIV-1, the spiked milk was diluted with PBS containing $10 \%$ FCS before addition to $\mathrm{CD} 4^{+} \mathrm{T}$ lymphocytes. On day 7 of culture, viral capsid (CA-p24) levels were determined by ELISA.

DC-SIGN-mediated HIV-1 transfer assay. The Raji and Raji-DC-SIGN cells were plated at $2 \times 10^{4}$ cells/well in a 96-well format. Dilutions of human milk or human milk compounds were made in PBS containing $10 \%$ FCS and spiked with $3.7 \log \mathrm{TCID}_{50} / \mathrm{ml}$ of the appropriate virus before addition to the Raji-DC-SIGN cells. As a control, PBS containing 10\% FCS was spiked with the same $\mathrm{TCID}_{50} / \mathrm{ml}$ of the corresponding virus before addition to Raji or Raji-DC-SIGN cells. After incubation the culture was washed with PBS before addition of $\mathrm{CD}^{+}$-enriched $\mathrm{T}$ lymphocytes at a concentration of $1 \times 10^{5}$ cells/well, with CA-p24 determined on day 7 .

$D C$-SIGN-specific Ab binding after exposure to human milk. Human milk was incubated with $50 \times 10^{3}$ Raji-DC-SIGN or iDCs for 15 minutes at $37^{\circ} \mathrm{C}$, after which the cells were washed with TSM $(20 \mathrm{mM}$ Tris, $150 \mathrm{mM}$ $\mathrm{NaCl}, 1 \mathrm{mM} \mathrm{CaCl}_{2}, 2 \mathrm{mM} \mathrm{MgCl}_{2}$ ) and the cells were incubated at $4^{\circ} \mathrm{C}$ for 45 minutes with $5 \mu \mathrm{g} / \mathrm{ml}$ of the specific DC-SIGN Ab, AZN-D1 (6), AZN-D2 (12), or anti-stalk 4. Subsequently, the cells were washed and incubated with goat anti-mouse FITC for 45 minutes at $4{ }^{\circ} \mathrm{C}$. The cells were washed and resuspended in $100 \mu \mathrm{l} \mathrm{TSM}$ containing $0.5 \%$ BSA (Fraction V, Fatty Acid-Free; Calbiochem), and the adhesion was measured by flow cytometry (BD Biosciences). 
DC-SIGN binding assay. For preincubation of HIV-1 with human milk, a 1:4 dilution of human milk or PBS containing $10 \%$ FCS was incubated with a high virus titer $\left(5.6 \log \mathrm{TCID}_{50} / \mathrm{ml}\right)$ of SF- 162 for 1 hour at $37^{\circ} \mathrm{C}$ before diluting the mixture to $1: 667$ by addition of $0.27 \times 10^{6}$ Raji-DC-SIGN cells in a 24-well format. The cells were incubated for 2 hours at $37^{\circ} \mathrm{C}$ before washing with PBS and addition of $\mathrm{CD} 4^{+} \mathrm{T}$ lymphocytes at a concentration of $1 \times 10^{6} \mathrm{cells} / \mathrm{ml}$ followed by measuring CA-p24 production on day 15 . For preincubation of Raji-DC-SIGN cells with human milk, a dilution of the human milk (1:4) or PBS containing $10 \%$ FCS was incubated with $0.27 \times 10^{6}$ Raji-DC-SIGN cells in a 24-well format for 1 hour at $37^{\circ} \mathrm{C}$ before washing with PBS and addition of SF-162 $\left(2.8 \log \mathrm{TCID}_{50} / \mathrm{ml}\right)$. The cells were incubated for 2 hours before washing and adding $1 \times 10^{6}$ cells/well of $\mathrm{CD}^{+}$-enriched lymphocytes, with CA-p 24 production measured on day 15 .

gp120 bead adhesion assay. Beads were prepared as previously described (6). In short, streptavidin was covalently coupled to carboxylate-modified TransFluoSpheres (488/645 nm excitation/emission, $1.0 \mu \mathrm{m}$; Invitrogen Corp.). The streptavidin beads were incubated with biotinylated $\mathrm{F}\left(\mathrm{ab}^{\prime}\right)_{2}$ fragment goat-anti-human IgG $(6 \mu \mathrm{g} / \mathrm{ml}$; Jackson ImmunoResearch Laboratories Inc.) and subsequently incubated overnight with gp120-Fc chimera. Fifty thousand Raji-DC-SIGN cells, iDCs, or Raji-L-SIGN cells were preincubated with human milk or milk compounds, AZN-D1 (6), AZN-D2 (12), EGTA, or mannan for 30 minutes at room temperature. The ligand-coated beads ( 20 beads/cell) were added to the preincubated cells and incubated for 30 minutes at $37^{\circ} \mathrm{C}$, after which the cells were washed with TSM containing $0.5 \% \mathrm{BSA}$. After washing, the cells were resuspended in $100 \mu 1$ TSM-BSA buffer, and the adhesion was measured by flow cytometry (BD Biosciences).

DC-SIGN-Fc binding ELISA. This assay utilized the DC-SIGN-Fc chimera, which contained the extracellular portion of DC-SIGN (amino acids 64-404) fused at the C terminus to a human IgG1 Fc fragment as previously described (56). Human milk or human milk compounds were diluted in $0.2 \mathrm{M} \mathrm{NaHCO}_{3}$, coated on ELISA plates (Maxisorp plate; Nunc), and incubated overnight at $4^{\circ} \mathrm{C}$ or 2 hours at $37^{\circ} \mathrm{C}$. This was followed by blocking with TSM containing $1 \% \mathrm{BSA}$ for 30 minutes at $37^{\circ} \mathrm{C}$ before addition of soluble DC-SIGN-Fc $(5 \mu \mathrm{g} / \mathrm{ml})$ for 2 hours at room temperature; the binding was determined by incubation of a peroxidase-labeled anti-IgG1 $\mathrm{Ab}$ for 30 minutes at room temperature. DC-SIGN-Fc binding specificity was determined by preincubation of the DC-SIGN-Fc with either $50 \mu \mathrm{g} / \mathrm{ml}$ DC-SIGN-specific mouse Ab AZN-D1 (6) or 10 mM EGTA.

Single-cycle-replication transmission assay. The assay was performed as previously described (58). In short, mDCs and iDCs were incubated in a 96-well plate $\left(35 \times 10^{3}\right.$ to $50 \times 10^{3} \mathrm{DCs} /$ well $)$ with human milk for 30 minutes at $37^{\circ} \mathrm{C}$ before addition of virus ( 5 ng CA-p24/well), which was incubated for 2 hours at $37^{\circ} \mathrm{C}$. The DCs were washed twice with PBS before addition of $50 \times 10^{3}$ LuSIV cells. After 24 hours, LuSIV cells were harvested and resuspended in $50 \mu$ lysis buffer ( $25 \mathrm{mM}$ Tris-Cl 7.8, $2 \mathrm{mM} \mathrm{DTT}, 2 \mathrm{mM}$ CDTA, $10 \%$ glycerol, $1 \%$ Triton X-100). The cells were then incubated for 45 minutes at room temperature while shaking, followed by 10 minutes centrifugation at 3,200 g. The supernatant was transferred to a white-solid 96-well plate (Costar; Corning), and $150 \mu \mathrm{l}$ of buffer $(100 \mu \mathrm{g} / \mathrm{ml} \mathrm{BSA,} 6.6 \mathrm{mM}$ ATP, $15 \mathrm{mM} \mathrm{MgSO}_{4}, 25 \mathrm{mM}$ glycylglycine) was added. One hundred microliters of DE(-)Luciferin (Roche Diagnostics $\mathrm{GmbH}$ ) was injected per well (0.28 $\mathrm{mg} / \mathrm{ml}$ lucibuffer excluding ATP). LuSIV cells $\left(50 \times 10^{3}\right)$ grown without DC or HIV-1 were used to obtain the background luciferase value.

Capture assay. To measure the capture of HIV-1 by iDCs, the cells were incubated in a 96 -well plate $\left(50 \times 10^{3} \mathrm{DCs} /\right.$ well $)$ with human milk for 30 minutes at $37^{\circ} \mathrm{C}$ before addition of the virus (5 ng CA-p24/well), which was incubated for 2 hours at $37^{\circ} \mathrm{C}$. The iDCs were washed twice with PBS before the CA-p24 concentration was determined by standard ELISA.

Statistics. All statistical comparisons were performed using ANOVA. $P<0.01$ and $P<0.05$ were considered statistically significant.

\section{Acknowledgments}

This work was funded through grants from the Elizabeth Glaser Pediatric AIDS Foundation (27-PG-51269), the Royal Dutch Academy of Arts and Sciences (to W.A. Paxton), and the Dutch AIDSfonds (7008). We are indebted to the mothers for providing milk samples and thank Michel de Baar for critical review of the manuscript, Stef Heynen for his expert technical assistance, and Wim van Est for the artwork.

Received for publication March 22, 2005, and accepted in revised form August 23, 2005.

Teunis B.H. Geijtenbeek and Georgios Pollakis contributed equally to this work.

Address correspondence to: William A. Paxton, Department of Human Retrovirology, Academic Medical Center, University of Amsterdam, Meibergdreef 15, 1105 AZ Amsterdam, The Netherlands. Phone: 31-20-5664739; Fax: 31-20-6916531; E-mail: w.a.paxton@amc.uva.nl.
1. Mitchell, D.A., Fadden, A.J., and Drickamer, K. 2001. A novel mechanism of carbohydrate recognition by the C-type lectins DC-SIGN and DCSIGNR. Subunit organization and binding to multivalent ligands. J. Biol. Chem. 276:28939-28945.

2. Weis, W.I., Taylor, M.E., and Drickamer, K. 1998. The C-type lectin superfamily in the immune system. Immunol. Rev. 163:19-34.

3. Yu Kimata, M.T., et al. 2002. Capture and transfer of simian immunodeficiency virus by macaque dendritic cells is enhanced by DC-SIGN. J. Virol. 76:11827-11836.

4. Geijtenbeek, T.B., et al. 2000. DC-SIGN, a dendritic cell-specific HIV-1-binding protein that enhances trans-infection of T cells. Cell. 100:587-597.

5. Pohlmann, S., et al. 2001. DC-SIGN interactions with human immunodeficiency virus type 1 and 2 and simian immunodeficiency virus. J. Virol. 75:4664-4672.

6. Geijtenbeek, T.B., et al. 2000. Identification of DCSIGN, a novel dendritic cell-specific ICAM-3 receptor that supports primary immune responses. Cell. 100:575-585.
7. Geijtenbeek, T.B., et al. 2000. DC-SIGN-ICAM-2 interaction mediates dendritic cell trafficking. Nat. Immunol. 1:353-357.

8. Wu, L., Martin, T.D., Carrington, M., and KewalRamani, V.N. 2004. Raji B cells, misidentified as THP-1 cells, stimulate DC-SIGN-mediated HIV transmission. Virology. 318:17-23.

9. Lozach, P.Y., et al. 2003. DC-SIGN and L-SIGN are high affinity binding receptors for hepatitis $\mathrm{C}$ virus glycoprotein E2. J. Biol. Chem. 278:20358-20366.

10. Pohlmann, S., et al. 2003. Hepatitis C virus glycoproteins interact with DC-SIGN and DC-SIGNR. J. Virol. 77:4070-4080.

11. Alvarez, C.P., et al. 2002. C-type lectins DC-SIGN and L-SIGN mediate cellular entry by Ebola virus in cis and in trans. J. Virol. 76:6841-6844.

12. Halary, F., et al. 2002. Human cytomegalovirus binding to DC-SIGN is required for dendritic cell infection and target cell trans-infection. Immunity. 17:653-664.

13. Tassaneetrithep, B., et al. 2003. DC-SIGN (CD209) mediates dengue virus infection of human dendritic cells. J. Exp. Med. 197:823-829.
14. Geijtenbeek, T.B., et al. 2003. Mycobacteria target DC-SIGN to suppress dendritic cell function. J. Exp. Med. 197:7-17.

15. Maeda, N., et al. 2003. The cell surface receptor DC-SIGN discriminates between Mycobacterium species through selective recognition of the mannose caps on lipoarabinomannan. J. Biol. Chem. 278:5513-5516.

16. Tailleux, L., et al. 2003. DC-SIGN is the major Mycobacterium tuberculosis receptor on human dendritic cells. J. Exp. Med. 197:121-127.

17. Colmenares, M., Puig-Kroger, A., Pello, O.M., Corbi, A.L., and Rivas, L. 2002. Dendritic cell (DC)-specific intercellular adhesion molecule 3 (ICAM-3)-grabbing nonintegrin (DC-SIGN, CD209), a C-type surface lectin in human DCs, is a receptor for Leishmania amastigotes. J. Biol. Chem. 277:36766-36769.

18. Colmenares, M., Corbi, A.L., Turco, S.J., and Rivas, L. 2004. The dendritic cell receptor DC-SIGN discriminates among species and life cycle forms of Leishmania. J. Immunol. 172:1186-1190.

19. Cambi, A., et al. 2003. The C-type lectin DC-SIGN (CD209) is an antigen-uptake receptor for Can- 
dida albicans on dendritic cells. Eur. J. Immunol. 33:532-538.

20. Appelmelk, B.J., et al. 2003. Cutting edge: carbohydrate profiling identifies new pathogens that interact with dendritic cell-specific ICAM-3-grabbing nonintegrin on dendritic cells. J. Immunol. 170:1635-1639.

21. Bergman, M.P., et al. 2004. Helicobacter pylori modulates the T helper cell $1 / \mathrm{T}$ helper cell 2 balance through phase-variable interaction between lipopolysaccharide and DC-SIGN. J. Exp. Med. 200:979-990.

22. Hu, J., Gardner, M.B., and Miller, C.J. 2000. Simian immunodeficiency virus rapidly penetrates the cervicovaginal mucosa after intravaginal inoculation and infects intraepithelial dendritic cells. J. Virol. 74:6087-6095.

23. Pope, M., Gezelter, S., Gallo, N., Hoffman, L., and Steinman, R.M. 1995. Low levels of HIV-1 infection in cutaneous dendritic cells promote extensive viral replication upon binding to memory CD4+ T cells. J. Exp. Med. 182:2045-2056.

24. Reece, J.C., et al. 1998. HIV-1 selection by epidermal dendritic cells during transmission across human skin. J. Exp. Med. 187:1623-1631.

25. Rowland-Jones, S.L. 1999. HIV: the deadly passenger in dendritic cells. Curr. Biol. 9:R248-R250.

26. Blauvelt, A., et al. 1997. Productive infection of dendritic cells by HIV-1 and their ability to capture virus are mediated through separate pathways. J. Clin. Invest. 100:2043-2053.

27. Cameron, P.U., et al. 1992. Dendritic cells exposed to human immunodeficiency virus type- 1 transmit a vigorous cytopathic infection to CD4+ T cells. Science. 257:383-387.

28. De Cock, K.M., et al. 2000. Prevention of motherto-child HIV transmission in resource-poor countries: translating research into policy and practice. JAMA. 283:1175-1182

29. Kourtis, A.P., Bulterys, M., Nesheim, S.R., and Lee, F.K. 2001. Understanding the timing of HIV transmission from mother to infant. JAMA. 285:709-712.

30. Nduati, R., et al. 2000. Effect of breastfeeding and formula feeding on transmission of HIV-1: a randomized clinical trial. JAMA. 283:1167-1174.

31. Rousseau, C.M., et al. 2003. Longitudinal analysis of human immunodeficiency virus type 1 RNA in breast milk and of its relationship to infant infection and maternal disease. J. Infect. Dis. 187:741-747.

32. Miotti, P.G., et al. 1999. HIV transmission through breastfeeding: a study in Malawi. JAMA 282:744-749.

33. Lewis, P., et al. 1998. Cell-free human immunodeficiency virus type 1 in breast milk. J. Infect. Dis. 177:34-39.

34. Dawarkadas, A.M., Saha, K., and Mathur, N.B. 1991. A comparative study of cells and anti-microbial proteins in colostrum of mothers delivering pre- and full-term babies. J. Trop. Pediatr. 37:214-219.

35. van't Wout, A.B., et al. 1994. Macrophage-tropic variants initiate human immunodeficiency virus type 1 infection after sexual, parenteral, and vertical transmission. J. Clin. Invest. 94:2060-2067.

36. Zhu, T., et al. 1993. Genotypic and phenotypic characterization of HIV-1 patients with primary infection. Science. 261:1179-1181.

37. Toniolo, A., et al. 1995. Productive HIV-1 infection of normal human mammary epithelial cells. AIDS. 9:859-866.

38. Messaoudi, K.E., et al. 2000. A human milk factor susceptible to cathepsin D inhibitors enhances human immunodeficiency virus type 1 infectivity and allows virus entry into a mammary epithelial cell line. J. Virol. 74:1004-1007.

39. Riley, J.L., et al. 1998. Naive and memory CD4 $\mathrm{T}$ cells differ in their susceptibilities to human immunodeficiency virus type 1 infection following CD28 costimulation: implications for transmission and pathogenesis. J. Virol. 72:8273-8280.

40. Bleul, C.C., Wu, L., Hoxie, J.A., Springer, T.A., and Mackay, C.R. 1997. The HIV coreceptors CXCR4 and CCR5 are differentially expressed and regulated on human T lymphocytes. Proc. Natl. Acad. Sci.U.S. A. 94:1925-1930.

41. Cameron, P.U., et al. 1996. The interaction of macrophage and non-macrophage tropic isolates of HIV-1 with thymic and tonsillar dendritic cells in vitro. J. Exp. Med. 183:1851-1856.

42. Stahl-Hennig, C., et al. 1999. Rapid infection of oral mucosal-associated lymphoid tissue with simian immunodeficiency virus. Science. 285:1261-1265.

43. Choi, Y.K., Whelton, K.M., Mlechick, B., MurpheyCorb, M.A., and Reinhart, T.A. 2003. Productive infection of dendritic cells by simian immunodeficiency virus in macaque intestinal tissues. J. Pathol. 201:616-628

44. Berkhout, B., et al. 2002. Characterization of the anti-HIV effects of native lactoferrin and other milk proteins and protein-derived peptides. Antiviral Res. 55:341-355.

45. Harmsen, M.C., et al. 1995. Antiviral effects of plasma and milk proteins: lactoferrin shows potent activity against both human immunodeficiency virus and human cytomegalovirus replication in vitro. J. Infect. Dis. 172:380-388.

46. Swart, P.J., et al. 1996. Antiviral effects of milk proteins: acylation results in polyanionic compounds with potent activity against human immunodeficiency virus types 1 and 2 in vivo. AIDS Res. Hum. Retroviruses. 12:769-775.

47. Lee-Huang, S., et al. 1999. Lysozyme and RNases as anti-HIV components in beta-core preparations of human chorionic gonadotropin. Proc. Natl. Acad. Sci.U. S. A. 96:2678-2681.

48. McNeely, T.B., et al. 1997. Inhibition of human immunodeficiency virus type 1 infectivity by secretory leukocyte protease inhibitor occurs prior to viral reverse transcription. Blood. 90:1141-1149.

49. McNeely, T.B., et al. 1995. Secretory leukocyte protease inhibitor: a human saliva protein exhibiting anti-human immunodeficiency virus 1 activity in vitro. $J$. Clin. Invest. 96:456-464.

50. Chaturvedi, P., Warren, C.D., Ruiz-Palacios, G.M., Pickering, L.K., and Newburg, D.S. 1997. Milk oligosaccharide profiles by reversed-phase HPLC of their perbenzoylated derivatives. Anal. Biochem. 251:89-97.

51. Kobata, A., Ginsburg, V., and Tsuda, M. 1969. Oligosaccharides of human milk. I. Isolation and char- acterization. Arch. Biochem. Biophys. 130:509-513.

52. Stahl, B., et al. 1994. Oligosaccharides from human milk as revealed by matrix-assisted laser desorption/ionization mass spectrometry. Anal. Biochem. 223:218-226.

53. Schwertmann, A., Rudloff, S., and Kunz, C. 1996. Potential ligands for cell adhesion molecules in human milk. Ann. Nutr. Metab. 40:252-262.

54. Van Die., I, et al. 2003. The dendritic cell-specific C-type lectin DC-SIGN is a receptor for Schistosoma mansoni egg antigens and recognizes the glycan antigen Lewis x. Glycobiology 13:471-478.

55. Newburg, D.S. 1996. Oligosaccharides and glycoconjugates in human milk: their role in host defense. J. Mammary Gland Biol. Neoplasia. 1:271-283.

56. Geijtenbeek, T.B., et al. 2002. Identification of different binding sites in the dendritic cell-specific receptor DC-sIGN for ICAM-3 and HIV-1. J. Biol. Chem. 277:11314-11320.

57. Bashirova, A.A., et al. 2001. A dendritic cell-specific intercellular adhesion molecule 3-grabbing nonintegrin (DC-SIGN)-related protein is highly expressed on human liver sinusoidal endothelial cells and promotes HIV-1 infection. J. Exp. Med. 193:671-678

58. Groot, F., et al. 2005. Lactoferrin prevents dendritic cell-mediated human immunodeficiency virus type 1 transmission by blocking the DC-SIGN-gp120 interaction. J. Virol. 79:3009-3015.

59. Guo, Y., et al. 2004. Structural basis for distinct ligand-binding and targeting properties of the receptors DC-SIGN and DC-SIGNR. Nat. Struct. Mol. Biol. 11:591-598.

60. Sanders, R.W., et al. 2002. Differential transmission of human immunodeficiency virus type 1 by distinct subsets of effector dendritic cells. J. Virol. 76:7812-7821.

61. Turville, S.G., et al. 2001. HIV gp120 receptors on human dendritic cells. Blood. 98:2482-2488.

62. Van Liempt, E., et al. 2004. Molecular basis of the differences in binding properties of the highly related C-type lectins DC-SIGN and L-SIGN to Lewis $\mathrm{X}$ trisaccharide and Schistosoma mansoni egg antigens. J. Biol. Chem. 279:33161-33167.

63. Su, S.V., et al. 2004. DC-SIGN binds to HIV-1 glycoprotein 120 in a distinct but overlapping fashion compared with ICAM-2 and ICAM-3. J. Biol. Chem. 279:19122-19132.

64. Okano, M., Satoskar, A.R., Nishizaki, K., and Harn, D.A., Jr. 2001. Lacto-N-fucopentaose III found on Schistosoma mansoni egg antigens functions as adjuvant for proteins by inducing Th2-type response. J. Immunol. 167:442-450.

65. Pabst, H.F., et al. 1997. Differential modulation of the immune response by breast- or formula-feeding of infants. Acta Paediatr. 86:1291-1297.

66. Roos, J.W., Maughan, M.F., Liao, Z., Hildreth, J.E., and Clements, J.E. 2000. LuSIV cells: a reporter cell line for the detection and quantitation of a single cycle of HIV and SIV replication. Virology. 273:307-315.

67. Pollakis, G., et al. 2001. N-linked glycosylation of the HIV type-1 gp120 envelope glycoprotein as a major determinant of CCR5 and CXCR4 coreceptor utilization. J. Biol. Chem. 276:13433-13441. 